Maria de Fátima Barbosa ABDALLA*

\title{
Formação e desenvolvimento profissional do professor: o aprender da profissão (um estudo em escola pública)
}

\section{Resumo}

Este texto tem o objetivo de compreender o conceito de necessidade como mudança ou direção desejada, para fundamentar a tese de que se novos saberes forem incorporados ao habitus dos professores, ampliando suas necessidades e perspectivas de trabalho, novos espaços de transformação serão criados no contexto da escola e da sala de aula - revelando uma maneira de ser e estar na profissão. Nesta perspectiva, este trabalho põe, em discussão, dois aspectos enfatizados pelos professores sobre a constituição de suas necessidades: $1^{\underline{0}}$ as necessidades e perspectivas que assumem em relação à formação e ao desenvolvimento profissional - a força da representação; e $2^{\circ}$ a importância que colocam na escola enquanto contexto de produção docente - locus da profissionalização docente.

\section{Abstract}

This text intends to understand the need's concept as change or wanted direction for supporting the thesis that if new knowledge is incorporate to the teachers' habitus, enlarging their needs and work perspectives, new transformation spaces will be created in the context of the school and classroom revealing the way of being in the profession. In this perspective, this work discusses two aspects emphasized by the teachers about the constitution of their identities: $1^{\circ}$ the needs and perspectives that they assume in relation to their formation and professional development - the force of the representation; and $2^{\circ}$ the importance that they place in the school as a context of educational production - locus of the educational professionalization.
Este trabalho apresenta o resultado parcial de minha reflexão sobre a construção do conhecimento pelos professores a respeito da própria prática, entendida aqui como espaço social concreto, revelando uma maneira de ser e de estar na profissão.

A perspectiva escolhida, uma das possíveis, é, em minha compreensão, válida e necessária, porque a maior parte de nós nos sentimos impotentes, ansiosos e inseguros a respeito do trabalho docente, especialmente, face às mudanças culturais e sociais, como bem acentua o professor da epígrafe acima. Discutir, assim, uma possível compreensão sobre o espaço da identidade do professor, no qual se articulam dimensões pessoais (da vida), profissionais (da profissão) e organizacionais (da escola), parece representar um ponto de partida.

Neste caminho, estarei pondo em discussão dois aspectos enfatizados pelos professores em suas representações sobre a constituição de suas identidades: as necessidades e perspectivas que assumem em relação à formação e ao desenvolvimento profissional que pretendem, e a importância que colocam na escola enquanto contexto de produção de sua profissionalização docente.

Do ponto de vista teórico, terei como apoio as idéias de Lefebvre $(1958,1991,1995)$ e Agnes Heller $(1977,1992)$, referentes ao estudo das representações e da cotidianeidade, e as de Bakhtin $(1988,1995)$ e Bourdieu $(1983,1987,1989$, $1990,1996,1997)$ que, ao se referirem ao campo das representações sociais, valorizam a fala como expressão das condições da existência. A compreensão da fala do professor exige ao mesmo tempo que entendamos as relações sociais que ela representa, o espaço da cotidianeidade e da história de ser professor.

*Doutora e mestre em Educação: Didática, USP. Licenciada em Pedagogia, Música e Letras. Professora das Faculdades Integradas "Campos Salles". 
Assim, partindo do suposto que a realidade vivida é também representada e que através dela os professores constroem sua vida e sua profissão, examinarei suas vozes, para compreender o que dizem sobre suas práticas. Nessa direção, pretendo apreender o modo com que estes professores estão-nomundo e de que forma desenvolvem o senso prático de ser e estar na profissão - o habitus, diria Bourdieu (1997). Habitus que orienta a percepção da situação profissional, a direção e o movimento que pretendem imprimir aos espaços concretos da escola e da sala de aula.

Os dados examinados ${ }^{1}$ aqui foram coletados durante os anos de 1996 a 1998. Detenho-me sobre os elementos que me levaram a analisar a questão central a que me propus neste trabalho: identificar como os professores aprendem a sua profissão (Canário, 1997), através do diagnóstico de suas necessidades. Necessidades da prática habitual - as representações dos professores a respeito das dificuldades, dos problemas identificados de forma individual ou coletiva. E necessidades para a prática desejada, aquelas que orientariam as metas especificadas, as mudanças desejadas, para criar um novo habitus.

Embora haja outros aspectos da pesquisa, o primeiro momento deste texto relaciona-se às representações dos professores sobre suas necessidades e perspectivas em busca da construção da identidade profissional. Para isso, estarei explorando as idéias apresentadas por Nóvoa (1992a), revendo, portanto, os conceitos de desenvolvimento profissional, tentando compreender até que ponto um olhar sobre as necessidades e perspectivas dos professores pesquisados pode ajudá-los a se posicionarem melhor em relação à profissão. Desenvolvo, também, o conceito de necessidade como mudança ou direção desejada (Rodrigues \& Esteves, 1993), para fundamentar a tese de que é possível gerar um novo habitus.

Em um segundo momento, ao pretender enfocar a escola enquanto contexto da ação do professor (Silva Júnior, 1991; Nóvoa, 1992a, 1992b; Penin,
1989, 1997; Marcelo García, 1994; Cunha, 1995. 1997; Sanmamed, 1995; Morais, 1997; Linhares, 1997; Canário, 1997; Cortella, 1998; Marin, 1998; Pimenta, 1997, 1998; entre outros), busco apreender seu significado como lugar onde os professores aprendem a sua profissão. Aprender a profissão no sentido de constatar as necessidades da escola, para mudá-la.

Na perspectiva de escrever sobre o desenvolvimento profissional, a partir de um olhar sobre as representações e práticas dos professores, importa ainda lembrar que nossos professores tomam a posição de sujeitos, falam a mesma língua, mas falam de modo diferente; abordam os mesmos assuntos, mas introduzem diversas inquietações. Como diria Bourdieu (1997: 29), a educação tornou-se bem mais comum, ainda que as diferenças sejam mantidas, mas no nivel dos lugares, dos momentos e das formas das práticas. Posso, enfim, dizer que há um movimento que traduz som e ruído, pois os professores (ou futuros professores) anunciam/enunciam/denunciam, identificam, assim, um ritmo que desafia qualquer harmonia. Um ritmo que imprime novos significados às formas de sentir e pensar, ao movimento de conhecer, fazer e transformar a prática docente em uma contínua interrogação epistemológica (Bourdieu, 1997: 202).

\section{Necessidades e perspectivas dos professores: em busca da construção da identidade profissional}

"O homemé, ao mesmo tempo, liberdade e necessidade: sua liberdade consiste numa necessidade compreendida, dominada e vencida; superada".

(Lefebvre, 1995: 114)

"(...) sinto a necessidade de me adequar às exigências da 'turma' com a qual trabalho - é necessário que eu reflita se men currículo está ou não adequado às condições sócio-econômicas e culturais; devo conhecer o lugar onde a escola está inserida e a sua história.

\footnotetext{
${ }^{1}$ Anotações escritas e material transcrito de gravações das falas dos alunos durante as aulas de Didática, do curso de Licenciatura, sob a responsabilidade da profa. dra. Selma Garrido Pimenta (de 1996 a 1997); video gravações das diferentes situações interativas da sala de aula de um professor de Geografia (egresso/ 1997); e transcrição das histórias de vida de outros egressos das diferentes turmas de Didática sob a coordenação da mesma professora (1998). Tais professores foram selecionados, porque trabalhavam (ou já haviam trabalhado) na rede pública de ensino do Estado de São Paulo.
} 
Estes aspectos são aspectos importantes que denotarão meu compromisso enquanto educador".

(profa. Delfina, Português/ 1997)

Até que ponto um olhar sobre as necessidades e perspectivas de professores pode ajudar a nos posicionarmos melhor em relação à nossa profissão? Quais seriam os efeitos epistemológicos deste olhar?

Da vasta discussão que aí se apresenta, a proposta básica é de desenvolver o conceito de necessidade como mudança ou direção desejada (Rodrigues \& Esteves, 1993: 17-18), para fundamentar a tese de que se novos saberes forem incorporados ao habitus dos professores, ampliando suas necessidades e perspectivas de trabalho, novos espaços de transformação serão cavados no contexto da escola e da sala de aula.

A partir deste conceito, coloco a questão da identidade, procurando explorar as noções de desenvolvimento pessoal, profissional e organizacional enunciadas por Nóvoa (1992a). Ao aproximar estas idéias dos registros das falas dos professores, duas hipóteses orientam meu pensamento. A primeira sustenta-se na força da representação, via análise das necessidades, como espaço possível de enfrentar os desafios da profissão. A segunda aposta na reflexão permanente sobre a prática como um modo de existência profissional. Reflexão que nos faz aprender a pensar nossas práticas para aprender a aprender (Demo, 1997; Freire, 1997; Libâneo, 1998) com nossas próprias experiências, aprendendo a ensinar a nós mesmos (Kincheloe, 1997: 196). Aprender para provocar mudanças no contexto da escola e da sala de aula, gerar um novo habitus. Aprender para apreender nossa própria formação e desenvolvimento profissional: uma forma necessária/desejada de articular teoria e prática, representação do mundo e mobilização de ações para transformá-lo.

\subsection{Do conceito de necessidade como prática} de definir objetivos de ação e de mudança: a força da representação

Centrando-me no inventário de problemas/di- ficuldades/expectativas ${ }^{2}$ assinalado pelos professores durante o tempo de coleta de dados (de 1996 a 1998), ou seja, nas representações sobre suas necessidades, pude verificar que estas são criadas, quando os professores as expressam. E quando isso acontece? Geralmente, na medida em que são instigados a falar e/ou a pensar sobre elas, mediante a criação de espaços/momentos favoráveis a alguma forma de conscientização das necessidades que cercam a profissão.

De posse dessa afirmação, ficou claro que o conceito de necessidade deveria ser explorado, se não fosse possível em sua abrangência, pelo menos naquilo que nos permitisse compreender como os professores aprendem a sua profissão.

$\mathrm{Na}$ verdade, quando falamos de nossas necessidades, nos diversos momentos e espaços profissionais, representamos nossas realidades, construímos nossas vidas, explicando-as mediante nosso estoque de conhecimentos. Essas representações podem ser consideradas matéria-prima para a análise do social mais amplo, como também direcionar uma ação pedagógico-política de transformação, pois, como diria Bakhtin (1995), elas retratam e refratam a realidade.

Com efeito, quando uma necessidade é expressa de forma consciente, ela faz um retrato, muitas vezes em preto e branco, da realidade, introduzindo as limitações objetivas do contexto a que se refere. Mas, por outro lado, traduz também uma intenção de ação a fim de transformar as condições existentes.

Partindo da palavra necessidade, assim está registrado no Novo Dicionário Aurélio (s/d: 966): "qualidade ou caráter de necessário - que não se pode dispensar; que se impõe; essencial; indispensável; aquilo que é absolutamente necessário; exigência; aquilo que é inevitável, fatal; aquilo que constrange, compele ou obriga de modo absoluto".

Mas o que é que consideramos essencial, indispensável, absolutamente necessário? De saída, podemos afirmar, com Monette, D'Hainaut, Mckillip (in Rodrigues \& Esteves, 1993: 13), que o conceito de necessidade se articula com a questão dos valores, pois é por intermédio deles que a necessidade se mede

${ }^{2}$ Para melhor classificar as necessidades dos professores, tanto na formação inicial, quanto nas ações de formação contínua, organizei dois quadros, em anexo, que tentam, de forma sintética, reproduzir as falas dos professores e dispô-las em possíveis categorias de análise. 
(D'Hainaut, id.:13), se qualifica, ou melhor, corporifica o caráter de necessário.

Dentro dessa perspectiva, outros autores definem tipologias variadas das necessidades, considerando que as mesmas são sempre relativas aos indivíduos e aos contextos. Dentre estes, Stuffelebeam (in Rodrigues \& Esteves, 1993: 16-19) se destaca, por ter realizado um apanhado geral das diferentes teorias, e porque apresenta uma certa aproximação com os dados da pesquisa. Ele aponta quatro concepções para definir o estudo sobre as necessidades: 1 . necessidades como discrepâncias ou lacunas; 2 . necessidades como mudança ou direção desejada por uma maioria; 3. necessidade como direção em que se prevê que ocorra um melhoramento; 4. necessidade como algo cuja ausência ou deficiência provoca prejuízo ou cuja presença é benéfica.

Para este estudo, tomo o conceito de necessidade como mudança ou direção desejada, formulado por Stuffelebeam, e parto da idéia, junto com Barbier e Lesne (id.: 1993: 24), de que analisar necessidades seria produzir objetivos de mudança para os indivíduos, ou seja, produzir objetivos indutores de formação. Analisar necessidades é, portanto, uma forma de intenção de ação e de mudança, seja ela do contexto e/ou da própria identidade profissional. Forma de intenção e de ação que transforma a maneira de ser e de estar na profissão.

Ao analisar as necessidades dos professores (durante a formação inicial e/ou nas ações de formação contínua ${ }^{3}$ ), observei que alguns aspectos (destacados por Rodrigues \& Esteves, 1993: 19), estavam presentes. Tais aspectos, a meu ver, giram em torno da necessidade como eixo de mudança ou direção desejada, pois estabelecem: 1. relação de dependência dos professores com os valores novos que vão impregnando a nossa sociedade (poderíamos traduzir aqui pelo reforço de legislações, como a LDB, os PCNs, as normas regimentais; pela construção do Projeto Político Pedagógico da Escola; e pelos Programas de Educação Continuada/PEC, entre outros); 2. subordinação dos professores ao contexto em que estes valores se determinam (articulando necessidades à política educativa); e 3 . multiplicação desses profissionais para divulgar novos valores/necessidades (via reuniões pedagógicas e de pais, comissões de classe, programas de formação contínua etc.).

Para além dos aspectos abordados pelas autoras, e tendo em vista os dados da pesquisa, temos que considerar ainda que a análise das necessidades expressa: $1^{\mathrm{o}}$ um espaço social global, como diria Bourdieu (1997: 50), um campo de forças ${ }^{4}$, onde os professores enfrentam os desafios de sua profissão (posição na hierarquia do trabalho), contribuindo para conservar ou transformar seu campo de atuação; $2^{\circ}$ mudanças desejadas no quadro de atividades pedagógicas, e em seus momentos de estruturação (planejamento, execução da ação ou em sua avaliação); e $3^{\circ}$ um significado essencial quando o professor puder, ao desvelar suas necessidades, se sentir pessoa, profissional e membro efetivo da equipe escolar. É, nestas dimensões, que se sustenta a força da representação: uma possibilidade de se induzir à ação, à mudança da ação e à formação do profissional professor.

Há ainda alguns pontos frágeis que não podem ser ignorados, especialmente, em relação ao trabalho coletivo da escola (traduzido pelas necessidades coletivas), e à formação do professor. Pontos que passam pelo entendimento: $1^{\mathrm{O}}$ da necessidade como unidade dialética entre o momento subjetivo das necessidades individuais, o intersubjetivo das necessidades coletivas, e o objetivo das limitações e possibilidades do contexto escolar; $2^{\circ}$ de estabelecer diferença entre os conceitos de necessidade e de preferência. Este último passa pela apreensão do que a maioria expressa, que pode não estar atenta de fato aos problemas essenciais da escola (questões de modismo ou temas não válidos para aquela comunidade); e 3 o de que necessidade deve levar à liberdade, ou seja, a algo que seja significativo, benéfico, portanto, valoroso. Algo que

${ }^{3}$ Em relação às ações de formação contínua, estou me reportando ao tempo de observação de sala de aula de um professor de Geografia (1997), egresso do respectivo curso de Didática (1996).

${ }^{4}$ Para a compreensão deste campo de forças, propomos a leitura das necessidades (ou parte delas) no Quadro 1, em anexo, que intitulei Necessidades dos professores na Formação Inicial e nas ações de Formação Contínua. Disponho, então, as necessidades dos professores em campos diferenciados: epistemológico, pedagógico, cultural e político-social. Campos onde se cruzam as forças da representação, via necessidades. 
possibilite, na relação de interdependência: negociar compromissos, ponderar vantagens e desvantagens, gerir contradições e conflitos, superar problemas, criar maneiras de ser e de estar na profissão (um novo habitus).

\subsection{Das necessidades pessoais do professor às} necessidades sociais: produzindo a profissionalização docente

“(...) não existe apenas um bom professor, isoladamente, que independa do local e das condições de trabalho em que se encontra. O que existe é, sim, o "grupo" do bom professor e é esse grupo que, unido por um projeto pedagógico comum, tornará possível, juntamente com a família do aluno, a formação do "cidadão" consciente de quem tanto se fala nos planejamentos de início de ano". (profa. Simone/Português, 1997)

Retomando os aspectos trabalhados anteriormente, centrados na questão da necessidade, e fazendo a releitura da fala da professora da epígrafe acima e de outros professores ${ }^{5}$, a proposta, agora, é de examinar mais de perto o conceito de identidade, na perspectiva de compreender como se articulam as dimensões pessoais, profissionais e organizacionais (Nóvoa, 1992a).

A idéia enunciada por Nóvoa (id.: 25) de que o professor é uma pessoa e é preciso dar um sentido à pessoa do professor, ao seu desenvolvimento, e ao contexto da escola em que trabalha, permite que entendamos como se constrói sua identidade. Tomamos estes conceitos para fazer uma breve reflexão sobre as necessidades da identidade do professor: necessidades pessoais (subjetivas), as coletivas/sociais (intersubjetivas) e as do contexto escolar (objetivas).

Quando refletimos sobre nossas experiências pessoais, compartilhamos necessidades e perspectivas de trabalho. Réfletimos sobre a nossa prática, nossas ações e condições de trabalho, apontando para intenções que se resumem na busca da inovação, da concretização dos projetos pessoais, no interior do projeto mais amplo profissional, e/ou do projeto concreto da escola, com o qual trabalhamos.

Portanto, esta maneira de expor nossas necessidades pessoais, trocando experiências com outros professores, revela uma forma de ser e de estar na profissão - porque faz com que partilhemos práticas, colocando em comum nossa profissão. Eé nessa troca que reconstruímos nossos saberes e competências ${ }^{6}$, compreendemos que nossas necessidades pessoais são necessidades coletivas/sociais, uma vez que as necessidades são sempre elaboradas e formuladas num dado contexto social (Rousson e Boudineu, in Rodrigues \& Esteves, 1993: 14).

Situando as necessidades pessoais/sociais em função da percepção das possibilidades disponíveis no espaço concreto da Escola, no campo de forças (Bourdieu, 1997), negociamos "coisas a fazer", formas de criar, maneiras a inventar, em resumo, nossa "pretensão de existir" (id.: 65). Colocamos, no jogo da vida, a possibilidade de exercer nossa profissionalidade. Profissionalidade que permite articular nossas representações e esquemas de ação - habitus (Bourdieu, 1997), em um espaço concreto, socializado pelas maneiras de pensar, decidir, avaliar ações e intenções. Profissionalidade que exige, para além dos saberes, competências que possibilitem mobilizar as representações em situação (Perrenoud, 1993: 179).

Para Perrenoud (1993: 184), a profissionalização será tanto melhor quanto os atores tenham uma concepção clara e exigente. Tal concepção passa primeiro, a meu ver, pela compreensão que se tem da prática habitual - das necessidades e das possibilidades pessoais (necessidades subjetivas), profissionais (necessidades intersubjetivas) que fundam e/ou são fundadas pelas exigências da escola (necessidades objetivas), em busca da prática desejada.

Os dados da pesquisa mostram-nos que, con-

\footnotetext{
${ }^{5}$ Vide o Quadro 2 - Das necessidades pessoais (subjetivas), profissionais (intersubjetivas) às necessidades organizacionais (objetivas) - para se obter um breve retrato das necessidades do alunos/professores entrevistados. Este quadro faz uma síntese, ainda que provisória, das representações dos professores sobre suas necessidades, enquanto pessoas/professores da escola pública do Estado de São Paulo (de 1996 a 1998).

${ }^{6}$ Tomo aqui emprestado o significado de competência de Le Boterf (in Canário, 1997: 5-6). Segundo este autor, a competência não é um estado, nem um saber que se possui, nem um adquirido de formação; só é compreensível "em ato" e daí o seu caráter finalizado, contextual e contingente.
} 
forme o grau de profissionalidade dos professores pesquisados ${ }^{7}$, o olhar da (e para a) realidade vai se ampliando com o exercício do trabalho docente. $\mathrm{Na}$ formação inicial, as necessidades são mais pessoais. Nas ações de formação contínua, no contato direto com os problemas da escola, as necessidades passam a ser mais enfocadas no trabalho coletivo, em busca de mudar o espaço concreto da escola e da sala de aula. E é nesta busca que se produz a profissionalização docente.

\section{A Escola enquanto contexto} fundamental de produção da profissionalização docente

"Eu não teria como enfrentar a sala de aula se fosse aquele professor que chegasse, olhasse para a classe sério, passasse um texto na lousa, e pedisse para o aluno copiar..." (prof. Silas / Geografia, 1997)

Os futuros-professores e/ou professores têm sido desorientados pelas mudanças constantes que a sociedade lhes impõe. Uma boa parcela dos professores busca o aconchego da rotina, das portas fechadas da sala de aula, da cumplicidade que trama com outros professores. Talvez porque tenham receio do novo; medo de se adaptarem. Faltamlhes confiança, consciência das possibilidades que têm enquanto educadores - vontade de intervir no mundo. Agarram-se, então, ao livro didático, aos saberes já adquiridos, às suas experiências. Não conseguem ou não querem seguir o ritmo da mudança, sobrevivem na e da educação.

Outros, como o prof. Silas, estão convencidos de que é mesmo preciso mudar a posição, enfrentar as incertezas e as inseguranças gestadas pelo mundo globalizado, pelas novas formas de trabalho e de produção. Para estes, o processo de mudança aguça-lhes a vontade de tomar decisões, e, com isso, assumem formas de sentir e pensar a realidade de seu trabalho, de sua profissão. Sentem-se parte da mudança (Enguita, 1998: 26), por isso, procuram gerir suas dificuldades e conflitos, buscam suprir suas necessidades e serem profissionais da educação. Por se sentirem e pensarem como profissionais, estimulam o trabalho coletivo, a troca de experiências, a investigação da própria prática. $\mathrm{E}$, com isso, problematizam a realidade, renovam saberes e atitudes, avançam na profissionalização.

É nesse sentido que vejo a escola enquanto contexto fundamental da profissionalização docente. Para justificar essa idéia, pretendo fazer uma breve retrospectiva da pesquisa...

Quando estávamos vivenciando as aulas de Didática, coordenadas pela profa. dra. Selma G. Pimenta (licenciatura/FEUSP), vimos que os alunos estavam preocupados em adquirir uma competência profissional. Competência que passava por um conteúdo formal de disciplinas e pela aquisição de técnicas/estratégias de ensino, ou seja, um saber-fazer voltado para o conhecimento em ação ou um saber em ação - saber teórico direcionado para a prática que intencionavam desenvolver. Era essa a necessidade primeira.

Entretanto, quando estes alunos já experimentavam os desafios da profissão, já se encontravam em um contexto de prática de ensino, as necessidades e interesses eram outros, porque eram mais concretos, orientados para a ação, relacionados a uma improvisação e uma conversação reflexiva. Tais professores, ou na aula da Didática ou contando suas histórias de vida, estavam cientes de que não poderiam estar subestimando a força da razão prática (Perrenoud, 1993: 30). Prática, em que "o indivíduo adquire, progressivamente, uma relação reflexiva com a sua própria formação e um certo domínio sobre as experiências às quais se submete ou se furta" (Perrenoud, 1995: 166).

Foi acompanhando as aulas do prof. Silas, no contexto de uma escola pública, que pude perceber mais nitidamente que o professor só se fazia como profissional, porque estava numa escola, fazia parte de um corpo coletivo de professores e alunos.

O conhecimento que o professor produzia sobre e para o ensino tinha como eixo norteador as necessidades da escola e de seus alunos, para além de suas próprias necessidades epistemológicas, pe-

\footnotetext{
7Vide quadros 1 e 2, em anexo.

${ }^{8}$ De março a outubro de 1997, acompanhei as aulas do prof. Silas Martim Junqueira (egresso da Didática/ 1996). As aulas eram do 1ํㅡㄹ ao 3 º colegial (hoje, ensino médio), período noturno da EEPSG "Emydio de Barros" (13ª DE, SP).
} 
dagógicas, político-sociais, culturais mais amplas ${ }^{9}$. Construía um conhecimento que provinha da ação e que direcionava as atividades que procurava realizar. Conhecimento que surgia das necessidades da prática, relacionadas a uma epistemologia da prática que se explica por uma teoria de ação. Teoria de ação que tem na prática o ponto de partida e o ponto de chegada. Teoria traduzida não só pelos saberes do conhecimento e pedagógicos, mas também, e, principalmente, pelos saberes da experiência e da interação com os outros sujeitos na construção de um practicum ${ }^{10}$ - onde o professor aprende ensinando, ensina pesquisando, aprende a aprender. Aprende à refletir sobre o seu saber-fazer docente, tematizando sua prática, dando conteúdo a suas formas de trabalhar em sala de aula, e de produzir a sua profissionalização docente.

Segundo o prof. Silas, a participação na pesquisa possibilitou-lhe uma prática de interrogação epistemológica e de sistematização do conhecimento que não tinha sido comum, nem para ele, nem para seus alunos. Tal postura permitiu ao professor compreender a importância do referencial teórico, não para aplicá-lo à realidade, mas para iluminá-la, abrindo perspectivas de teorizar sobre a mesma, contribuindo para a reflexão do seu saber-fazer e de seus alunos. Um dos efeitos deste novo habitus evidenciou a necessidade de uma maior confiabilidade na participação dos alunos no processo da aula e de investigação dos problemas suscitados pelas diferentes experiências. Para isso, o professor incentivou seus alunos a realizarem trabalhos em grupo, seminários, leituras significativas e visitas extra-curriculares, integrando-os, também, nos diferentes projetos da escola.

Uma outra mudança sentida pelo prof. Silas foi o fato dele estar ressignificando o contexto da escola, enquanto produção de sua profissionalização docente, refletindo mais pontualmente sobre as maneiras de ser e estär na profissão professor. Nesse sentido, o esforço despendido por ele foi posteriormente avaliado por seus alunos, que também consideraram a pessoa do professor, ao lado do profissional. $\mathrm{E}$ isso fez com que alguns alunos valorizas- sem o ensino da Geografia através do modo/da didática com que o professor conduziu suas aulas. Eis alguns comentários ${ }^{11}$ :

"O curso foi muito bom, pois discutimos temas polêmicos que nos incentivaram a expor nossas idéias e o nosso ponto de vista. As aulas dinâmicas incentivaram os alunos a terem uma certa amizade com o professor e isso não é muito comum, mas gostamos da experiência".

“(...) possibilitou uma integração mais prazerosa, onde pudemos trocar os conhecimentos. O trabalho em coletividade deixa o conteúdo da matéria mais fixado em nossas mentes e em nossas vidas".

2.1. Imprimindo um senso prático de ser e estar na profissão: da prática habitual à prática desejada (ao novo habitus)

A troca de experiências com os professores egressos do curso de Didática, especialmente, no contato direto com o prof. Silas, possibilitou um repensar de nossas necessidades pessoais/profissionais, e da escola enquanto contexto fundamental da profissionalização docente. Essa era uma maneira de imprimir um novo habitus - princípio gerador de práticas distintas e distintivas (Bourdieu, 1997: 22), transformando a nossa prática habitual em pelo menos quatro dimensões (Abdalla, 1997):

- pessoal - na medida em que ajudou a organizar nossas necessidades pessoais, os saberes de nossas experiências, ampliando os saberes do conhecimento específico e os pedagógicos - construindo nossas identidades de professor (e de professor-pesquisador);

- didática - quando (re)aprendemos a planejar, a (re)conhecer os conteúdos dos programas e a enfrentar os desafios das situações pedagógicas e das questões metodológicas, em um processo de partir das intenções às ações, e das ações às intenções renovadas - ampliando o ciclo didático (planejando, executando, avaliando, (re) planejando...);

- institucional/organizacional - intensificando o sentido do ensino como prática social viva - nos con-

\footnotetext{
${ }^{9}$ Vide Quadro 1, em anexo, para melhor esclarecimento dos campos das necessidades.

${ }^{10}$ Utilizo-me do termo practicum, como momentos estruturados da prática pedagógica (Zeichner, 1992: 117).

${ }^{11}$ Vide, em anexo, o Quadro 3 que se refere a alguns trechos das avaliações dos alunos a respeito do trabalho do prof. Silas.
} 
textos sociais e institucionais nos quais ocorrem ( $\mathrm{Pi}$ menta, 1998: 156) - ressignificando o entorno da sala de aula, contextualizando as experiências de ser e estar professor em espaços mais amplos, entrando em contato com uma série de temáticas que só são possíveis, porque agora pensamos em termos de Escola, de Projeto Político-Pedagógico, de Sistema de Ensino, de políticas públicas etc.

- profissional - quando aprendemos a ser práti$\cos$, adaptando os conhecimentos teóricos à realidade escolar, mas, mais do que isso, reconstruindo a teoria pela via da prática. Reconstrução que passa, muitas vezes, pela desconstrução dos conhecimentos adquiridos e pela co-construção, porque compartilhada através da troca de experiências.

Da prática habitual à prática desejada, ainda há muitas interrogações: Como fazer com que o professor se assuma no exercício de sua profissão? Como estimular professores a se envolverem em uma prática coletiva que ressignifique o papel da escola frente às novas exigências educacionais? Como levar adiante um projeto emancipatório de educação? Como construir uma identidade profissional que possibilite ao professor a aprender a pensar e a aprender a aprender (Kincheloe, 1993; Freire, 1997; Libâneo, 1998; Pimenta, 1998, entre outros) sua própria prática, assumindo a convicção de que a mudança é possível e é necessária (Freire, id.: 85-94)? Talvez sejam estas as primeiras questões a serem enfrentadas por qualquer projeto que leve em conta a formação inicial e/ou contínua de educadores nas nossas escolas e universidades.

\section{Ainda algumas considerações}

O exercício realizado neste trabalho deixa entrever alguns direcionamentos interessantes que confirmam as nossas considerações a respeito do pressuposto de que, se novos saberes forem incorporados ao habitus dos professores, estaremos não só investindo em sua profissionalização, mas também criando espaços concretos de transformação, no contexto da escola e/ou da sala de aula. Para isso, considero que olhar para as necessidades dos professores (na formação inicial e/ou contínua) pode ajudá-los a enfrentarem os desafios da profissão, produzindo objetivos de ação e de mudanças na própria prática.

Na tentativa de pensar em como transformar necessidades em objetivos de ação e de mudança, gerando um novo habitus, apresento algumas teses, já desenvolvidas em um outro trabalho (Abdalla, 1997):

Tese $n^{\boldsymbol{o}} \mathbf{1}$ - O caminho da formação e do desenvolvimento profissional se sustenta na busca de compreender e superar as necessidades da própria profissão - na força da representação. Força que se alimenta da reflexão permanente sobre a prática, entendida aqui como um modo de existência profissional - maneiras de ser e estar na profissão.

Tese $n^{\underline{0}} 2$ - Quando o professor aponta como necessidade a reflexão sobre o seu saber-fazer docente, tematizando sua prática, dando conteúdo a suas formas de trabalhar em sala de aula, abre possibilidades de mudanças em sua prática. Mudanças que passam a configurar o ensino como lugar da pesquisa e a pesquisa como o lugar da aprendizagem. A pesquisa torna-se, então, princípio cognitivo de compreensão da realidade e princípio formativo na docência (Pimenta, 1997:51).

Tese $n^{0} \mathbf{3}$ - Para que o ensino passe a ser o lugar da pesquisa e a pesquisa o lugar da aprendizagem, é importante que se abram espaços (no interior da Escola e em outros contextos, em especial, na Universidade), que propiciem regularmente um tempo para professores descreverem, discutirem, registrarem suas situações didáticas, reafirmando, assim, a importância da troca de experiências. É neste compartilhar que se permite um fluxo rico em diálogo e dados em torno das necessidades pessoais/profissionais/organizacionais, tanto no curso de formação inicial, quanto nas ações de formação contínua.

Tese $n^{0} 4$ - A possibilidade de um trabalho investigativo da própria prática, dos saberes da experiência, dos saberes científicos e dos saberes pedagógicos (Pimenta, 1997: 42-52), considerando a identidade do professor em suas dimensões pessoais, profissionais e organizacionais (Nóvoa: 1992a), leva a uma necessidade contínua de um melhor conhecimento, para fazer frente às novas exigências educacionais, e de uma educação mais comprometida com a cidadania dos educandos, na possibilidade de uma abertura para uma sociedade mais justa, democrática e humana. 
Em conseqüência desses aspectos, pensamos, concluindo, que é fundamental perspectivar a formação de professores, inicial e contínua, partindo do que denominamos de princípios estruturantes:

\section{1 o princípio}

Considerando que o caminho de formação e desenvolvimento profissional se sustenta na busca de compreender e superar as necessidades da própria profissão, os programas de formação e de desenvolvimento profissional não podem desprivilegiar a análise de necessidades centradas nos interesses e expectativas dos professores, enquanto pessoas, profissionais e membros de uma organização institucional. O que implica pensar, sobretudo, nas ações do dia-a-dia e na compreensão de que os professores apresentam diferentes necessidades/expectativas, que revelam conteúdos diversificados e que precisam ser superadas. A escola deve, então, aprender com seus professores a fazer uma seleção das necessidades predominantes do grupo em questão.

\section{$2^{2}$ princípio}

Se se considerar que formar é orientar os indivíduos para o conhecimento e para as mudanças, a escola, como instituição social, precisa se esforçar para abrir possibilidades de mudança em suas próprias práticas. Sabemos, no entanto, que não basta querer, é preciso buscar estratégias de mudanças, que possam intervir e mudar a maneira (a "cara") da escola. Entretanto, vimos, na prática, que as representações, as práticas e a cultura escolar e/ou profissional não mudam por decreto. Para transformar a ação e a formação do professor, não bastam reformas impostas, mas há necessidade de se pensar em reformas compostas, portanto, compartilhadas pelo coletivo da escola.

A formação para a mudança passa, necessariamente, por um processo de negociação, entre os professores, direção e coordenação, que afirme e confirme uma espécie de contrato permitindo (re)conhecer, (re)fazer e (trans)formar as práticas no interior da escola, para além das reformas que levam em conta as orientações do Ministério da Educação, dos Conselhos Educacionais e/ou das Secretarias de Educação.

\section{3ำ princípio}

Uma análise reflexiva do processo de negociação entre aqueles que estão engajados e pretendem inovar a escola tem na pesquisa, centrada nas situações específicas da prática pedagógica, a estratégia de formação de seus professores. Pensando no ensino, enquanto o lugar da pesquisa, e, na pesquisa, enquanto lugar da aprendizagem, é que a escola começa a implementar mudanças. $\mathrm{O}$ que permite, também, um fluxo rico em diálogo e dados em torno das necessidades pessoais/profissionais/organizacionais.

Para isso, a escola precisa abrir espaços no seu interior e em outros contextos, em especial, em parceria com a universidade. Espaços que possam propiciar, regularmente, um tempo para professores descreverem, discutirem e registrarem suas situações de ensino (do aprender da profissão). E isso implica busca de informação, leitura sistemática, acompanhamento das novidades e troca de experiências.

Implica, portanto, transformar as ações de desenvolvimento em redes de atuação que valorizem estratégias de aprendizagem da profissão em relação à: a) tomada de consciência em torno de resolução de problemas; b) aprendizagem de formas de tratamento das diferentes informações; c) explicitação das representações e práticas dos professores; e d) reconstrução dos saberes através da organização, articulação e análise dos projetos e dos processos de condução e regulação dessas ações. Para nós, isso seria uma maneira de transformar conhecimento sobre o ensino em um currículo coerente para aprender a ensinar (Barnes, 1989: 20).

\section{4º princípio}

Tornar a formação como componente determinante da mudança e integrada no próprio exercício da profissão. O que implica, sobretudo, refletir sobre a necessidade contínua de um melhor conhecimento, para fazer frente às novas exigências educacionais, e de uma educação mais comprometida com a cidadania dos educandos, na possibilidade de uma abertura para uma sociedade mais justa, democrática e humana.

Estes princípios estruturantes são apenas um guia para o aprender da profissão e um esforço para ressignificar a formação e o desenvolvimento do pro- 
fissional professor, pois o que vale, enfatiza Bourdieu (1998a: 361), é a consciência teórica e epistemológica que acompanha estas operações.

Enfim, descortinar um projeto profissional de construção e produção do sentido no conjunto das práticas educacionais é uma tarefa árdua, mas não impossível, desde que saibamos ouvir das diferentes vozes, nem sempre harmoniosas, aquelas que apontam insistentemente para o transformar da escola.

\begin{tabular}{|c|c|}
\hline & Quadro 1 \\
\hline Campo ${ }^{12}$ & Necessidades dos professores na Formação Inicial e nas ações de Formação Contínua* \\
\hline Epistemológico & $\begin{array}{l}\text { - aprendizagem de saberes sobre: } \\
\text { - o conteúdo do que ensinar (a matéria/disciplina) } \\
\text { - o processo de ensinar (aprender ou reaprender o que é o ensino) } \\
\text { - o processo de aprendizagem (entender o universo da aprendizagem) }\end{array}$ \\
\hline Pedagógico & $\begin{array}{l}\text { - aprendizagem do saber-fazer e das técnicas: } \\
\text { - conhecer a forma do conhecimento } \\
\text { - o caminho metodológico (o modo/a maneira de transmitir o conhecimento sobre o fazer- } \\
\text { ensinar) } \\
\text { - compreender os aspectos pedagógicos (para ministrar da melhor forma as aulas) } \\
\text { - aprender novas técnicas (técnicas eficientes para a utilização em sala de aula; provocar } \\
\text { situações pedagógicas mais interessantes, mais próximas dos alunos) }\end{array}$ \\
\hline Cultural & $\begin{array}{l}\text { - aprendizagem do capital cultural (sistema de significados, disposições, gostos, atitu- } \\
\text { des e normas): } \\
\text { - visão mais ampla do papel e do significado de ser professor (discutir e refletir sobre } \\
\text { nosso papel como professores no processo ensino-aprendizagem) } \\
\text { - estar voltado para a realidade (compreender as mudanças - os avanços tecnológicos; os } \\
\text { diferentes contextos; entender o comportamento dos alunos; as relações professor / pro- } \\
\text { fessor; professor / alunos etc.) }\end{array}$ \\
\hline Político-Social & $\begin{array}{l}\text { - tomadas de consciência a respeito das normas das instituições; das relações de força, } \\
\text { das implicações sociais: } \\
\text { - as políticas educacionais (que determinam o dever ser da escola) } \\
\text { - entender como funciona a Escola (o que ela tem, o que não tem, o que falta) } \\
\text { - compreender as relações interpessoais (os embates com a burocracia; a resistência dos } \\
\text { professores; a necessidade de um trabalho coletivo e da troca de experiências) }\end{array}$ \\
\hline Campo & Necessidades de Formação Contínua** \\
\hline Epistemológico & $\begin{array}{l}\text { - saber sobre } \\
\text { - reforço escolar } \\
\text { - aceleração } \\
\text { - flexibilização } \\
\text { - PCNs } \\
\text { - Salas-ambiente } \\
\text { - Projeto Político-Pedagógico }\end{array}$ \\
\hline Pedagógico & $\begin{array}{l}\text { - saber-fazer: } \\
\text { - material pedagógico e cursos com orientação metodológica } \\
\text { - discussão de estudos de caso (onde podemos detectar o sintoma, diagnosticamos estu- } \\
\text { dando o mesmo, propomos o tratamento e supomos o prognóstico) }\end{array}$ \\
\hline
\end{tabular}

12. Tomo emprestado de BOURDIEU (1997: 50) o termo campo para expressar o espaço social global e ao mesmo tempo um campo de forças, onde os professores enfrentam os desafios de sua profissão (posição na hierarquia do trabalho), contribuindo para conservar ou transformar seu campo de atuação, delimitando-o, petrificando-o e/ou ampliando seus limites e possibilidades. 
Quadro 1 (continuação)

\begin{tabular}{l|l}
\hline Cultural & - questões sobre o contexto cultural: \\
& - concepção de mundo e de sociedade (visão crítica/consciência filosófica/ lutar por um \\
& mundo mais justo/ mudança de atitude/ maturidade para refletir sobre os fatos) \\
& - acompanhamento das mudanças (reflexão/ incorporação crítica dos avanços tecnológicos) \\
& - trabalho com a comunidade (promover uma prática de integração)
\end{tabular}

*Entre parênteses registram-se trechos das falas de alunos da Didática ${ }^{13}$ (alguns já professores da rede estadual de ensino do Estado de São Paulo)

**As histórias de vida ${ }^{14}$ revelaram a necessidade de se discutir e/ou buscar esclarecimentos em relação a temas mais próximos do cotidiano escolar

\begin{tabular}{|c|c|}
\hline & Quadro 2 \\
\hline & $\begin{array}{l}\text { Das necessidades pessoais (subjetivas), profissionais (intersubjetivas) às } \\
\text { necessidades organizacionais (objetivas) }{ }^{15}\end{array}$ \\
\hline $\begin{array}{l}\text { Necessidades } \\
\text { Pessoais } \\
\text { (subjetivas) }\end{array}$ & $\begin{array}{l}\text { - Verificar se estou transmitindo de maneira correta o conteúdo de minha disciplina; } \\
\text { aprender a ministrar da melhor forma as minhas aulas; uma forma exata de como } \\
\text { lecionar; técnicas eficientes para a utilização em sala de aula; maneiras e méto- } \\
\text { dos de ensinar o conteúdo; formas educacionais; metodologias; aprender a meto- } \\
\text { dologia a ser usada em sala de aula; } \\
\text { - Como enfrentar, o que fazer dentro da minha sala de aula, tendo em vista todos } \\
\text { os problemas que a escola pública vem enfrentando; adquirir conhecimento espe- } \\
\text { cífico sobre o fazer-ensinar; } \\
\text { - Aprender ou reaprender o que é o ensino, a escola, o aluno, o professor, enfim, o } \\
\text { universo da aprendizagem; adquirir subsídios para compreender melhor a relação } \\
\text { professor-aluno, professor-professor; entender o comportamento dos meus alu- } \\
\text { nos; } \\
\text { - Além da teoria trazer também a prática, mostrar as várias possibilidades de ensi- } \\
\text { no; conteúdos que possam passar pelos aspectos essenciais, indo da concepção } \\
\text { da escola à prática cotidiana; necessidade de compreensão teórica de certos as- } \\
\text { pectos pedagógicos que não são claros, pelo menos, para mim; } \\
\text { - Aprender e apreender métodos e alternativas de aula, de modo que meus alunos } \\
\text { tenham conhecimento de cidadãos e agentes dos processos históricos; } \\
\text { - Necessidade de crescimento pessoal e profissional; boas idéias e novas inquieta- } \\
\text { ções e perspectivas (abertura de novas portas); avaliar meus acertos e meus } \\
\text { erros; } \\
\text { - Receber informações sobre a atuação do professor em sala de aula, para poder } \\
\text { melhorar as minhas ações; }\end{array}$ \\
\hline
\end{tabular}

${ }^{13}$ Refiro-me aqui à pesquisa de campo que fiz junto aos alunos de Didática, do curso de Licenciatura/FEUSP, sob a coordenação da profa. dra. Selma Garrido Pimenta (1996 a 1997).

${ }^{14}$ As histórias de vida de alguns dos alunos egressos da Didática, já atuando nas escolas estaduais de São Paulo (1998), representam um terceiro movimento da pesquisa empírica. Para situar estes momentos: 1 o observação das representações dos alunos a respeito das necessidades profissionais (1996 a 1997); 2ำ acompanhamento de um aluno deste curso no contexto da escola pública (março a outubro de 1997, na EEPSG "Emydio de Barros" - prof. Silas/Geografia); 3ํo coleta de depoimentos com outros alunos de diferentes turmas, mas sob a coordenação da mesma professora (1998).

${ }^{15}$ Foram selecionados, para este quadro, apenas alguns trechos das histórias de vida dos professores que expõem suas necessidades pessoais/profissionais/organizacionais, tanto no curso de formação inicial, quanto nas ações de formação contínua. 
- Auxiliar os outros a aprenderem cada vez mais;

- Descobrir, portanto, a necessidade de se fazer um bom planejamento, levando-se em conta principalmente os alunos, os objetivos do curso, as condições reais de trabalho, o tempo disponivel para o curso; e mais, do fazer o planejamento, entendo hoje a necessidade de revisá-lo e reorientá-lo, caso necessário. Repensando a função do planejamento, repensei também a organização de minhas aulas (às vezes, elas pareciam um pouco confusas e com propósitos pouco claros) e o meu rigor como professora (em alguns momentos não sabia o que podia esperar dos meus alunos). No ano de 1998 , pretendi encarar o desafio de fazer do planejamento algo vivo, eficaz e acima de tudo um instrumento útil para orientar meus cursos;

- O que mais tenho necessidade e o que mais me motiva a dar aula é exatamente a troca com os alunos: é você poder mostrar coisas para eles, para que eles possam mostrar coisas para você;

- Necessidade de ter sempre que estar repensando, porque a gente tem que refletir, porque o mundo está mudando a cada dia. Então, a cada dia tenho que refletir sobre o que estou fazendo, se está certo ou está errado. Eu acho que é isto que é ser um bom professor, é sempre estar refletindo, repensando o que se está fazendo...

- Eu acho que a gente fica um pouco cansado, acho que chega uma hora assim que você rema tanto ... rema tanto contra a maré, que você tira o remo da água e o barco vai indo, deixa se levar.. Você se entrega... (...) Mas olha... tenho uma necessidade de ser bom professor. E ser bom professor, para mim, é acreditar no aluno, é gostar do aluno, é ter esperança no aluno. Ser professor é ter um bom relacionamento com o aluno, é ser amigo do aluno, é trocar experiências com o aluno. Eu acho que ser bom professor (falou vagarosamente) está no saber lidar com o aluno, refletindo...

Necessidades

Profissionais

(intersubjetivas)
- Pensar em nossa prática pedagógica; discutir e refletir sobre nosso papel como professores no processo ensino-aprendizagem; receber informações sobre a atuação do professor em sala de aula; mais do que aprender técnicas, ter uma visão mais ampla do papel e do significado de ser professor (só sinto que onde trabalho as coisas sejam tão difíceis, e penso que o sistema como um todo não me permitiria tentar aplicar novas idéias que estão surgindo na minha mente);

- Preparação melhor das 3 HTPCs semanais, de forma prática e produtiva; estudo de situações* em que possamos fazer uma análise crítica e comparativa do técnico teórico que foi usado como metodologia, e assim, propor soluções, gerar mais questionamentos e aí buscar a resposta na discussão do grupo e leitura de textos complementares; fazer com que os professores de uma forma conjunta trabalhem os temas transversais vinculados aos conteúdos e articulados ao Projeto PolíticoPedagógico;

- Fazer com que os professores, de uma forma conjunta, trabalhem os temas transversais vinculados aos conteúdos, e articulados ao Projeto Político-Pedagógico;

- Quebrar as resistências de alguns professores;

- Necessidade de uma profissão melhor remunerada;

- Que os professores se organizem para estudar a situação do ensino no Brasil, e juntamente com os alunos revolucionem tudo;

- A busca, a procura do melhor caminho. Acho que esta busca deve ser coletiva. Ser bom professor é realizar esta busca, integrar os jovens neste processo. O bom professor é também aquele que tem concepção de mundo baseada numa consciência filosófica, percebe não só que o mundo muda e que também é necessária a mudança por carregar dentro de si carga enorme de injustiça. Lutar por um mundo desejado, justo. Necessidade de ter visão crítica;

- Necessidade de se trabalhar em conjunto, é o corpo docente, não dá para ser o professor... Para alguém chegar a ser um bom professor, antes de mais nada, ele vai ter que sempre estar buscando ser o bom professor, porque nós trabalhamos com um material humano, criança, adolescente, e não tem como... Eu não acrédito que ser o bom professor hoje serviria para daqui a dez anos. O nosso público 


\section{Quadro 2 (continuação)}

\begin{tabular}{|c|c|}
\hline & $\begin{array}{l}\text { transforma-se, a nossa sociedade toda se transforma, mas o público - a criança, o } \\
\text { pré-adolescente e o adolescente - eles mudam e eles sofrem a ação dessas mu- } \\
\text { danças da sociedade. Insisto, antes, eu me atinha muito à questão do conteúdo, } \\
\text { está sempre atualizando, renovando... mas não é só isso. É o todo... tem que } \\
\text { estar aberto à transformação... não é que ele tenha que violentar os princípios } \\
\text { dele, os objetivos, não é isso... mas tem que estar aberto a este público e buscan- } \\
\text { do sempre ser um bom professor; } \\
\text { - o que é necessário, então, para que alguém se torne um bom professor? Ele pode } \\
\text { ter sido educado em um ambiente propício e com influências positivas quanto à } \\
\text { carreira, mas o essencial é que o professor tenha aptidão (competência e sabedo- } \\
\text { ria) para lidar com o conhecimento, visto que é esse o objeto ou a matéria-prima } \\
\text { de seu trabalho. (...) o professor deve levar à reflexão e, para isso, é preciso que } \\
\text { se tenha em mente os objetivos que se quer alcançar com esses ensinamentos. O } \\
\text { primeiro ponto em questão, portanto, o dos objetivos do ensino, nos leva a um } \\
\text { outro ponto fundamental num ensino de qualidade: não existe apenas um bom } \\
\text { professor, isoladamente, que independa do local e das condições de trabalho em } \\
\text { que se encontra. o que existe é, sim, o 'grupo' do bom professor e é esse grupo } \\
\text { que, unido por um projeto pedagógico comum, tornará possível, juntamente com } \\
\text { a família do aluno, a formação do 'cidadão' consciente de quem tanto se fala nos } \\
\text { planejamentos de início de ano. }\end{array}$ \\
\hline $\begin{array}{l}\text { Necessidades } \\
\text { Organizacionais } \\
\text { (objetivas) }\end{array}$ & $\begin{array}{l}\text { - Estar preocupado muito com a realidade, com a prática da escola, como é que } \\
\text { funciona lá, vamos ver que escola é esta, o que ela tem, o que não tem, o que } \\
\text { falta. Isso é essencial para quem vai dar aula. Este é o primeiro ponto; } \\
\text { - Ter um diagnóstico preciso da Escola, para que o trabalho seja realizado com base } \\
\text { nas necessidades da UE; } \\
\text { - Necessidade de segurança nas escolas; } \\
\text { - Necessidade de uma mudança de atitude política desse país, caso contrário a } \\
\text { educação entrará em colapso... Acho que a educação está um caos. O governo } \\
\text { não valoriza quase nada, não melhora o salário, e cria programas de formação } \\
\text { que na maioria é só fachada, já que os professores não têm condições de aplicar } \\
\text { o que viram com os alunos; } \\
\text { - Necessidade de que a escola e o sistema de ensino ofereçam subsídios para o } \\
\text { Projeto Político Pedagógico/ Sala-Ambiente; esclarecimentos/ orientações/ livros } \\
\text { paradidáticos e apostilas para os professores sobre aceleração, reforço escolar, } \\
\text { flexibilização etc.; aprofundamento das questões referentes aos Parâmetros Cur- } \\
\text { riculares Nacionais (PCNs); cursos mais práticos para facilitar o nosso trabalho; } \\
\text { material pedagógico em geral; } \\
\text { - Necessidade de se pensar o que é que tem feito o jovem perder o interesse... de } \\
\text { modo geral os valores... Mas acho que não se deve perder a esperança, não. Tem } \\
\text { que se procurar uma maneira de estar incentivando... e a escola é o local, é o } \\
\text { local...não é um local, é o local. É necessário organizá-la para isso. }\end{array}$ \\
\hline professora & $\begin{array}{l}\text { nenta sua fala: Não sei se fui clara, seria um estudo de caso, onde se detecta o } \\
\text { os, estudando o mesmo, propomos o tratamento e supomos o prognóstico. A educa- } \\
\text { ser vista desta forma, pois lidamos diretamente com o processo psico-físico-social do } \\
\text { ma máquina. }\end{array}$ \\
\hline
\end{tabular}

\section{Quadro 3}

Alguns trechos das avaliações dos alunos de um professor egresso da Didática

Foi excelente, aprendemos o essencial. Aprendemos sobre a realidade dos sem-terras, e como o governo não se comove. Se todo brasileiro soubesse votar direito, com certeza, nas próximas eleições, teríamos um país melhor. (Carmem e Andréa, $2^{\circ} \mathrm{A}$ )

- O curso e a metodologia foi super bom, pois pudemos aprender muitas coisas, esperamos que sempre possamos ter esses conhecimentos e, no próximo ano, aprendermos mais ainda. Obrigado por tudo. Feliz Natal... (Luciana e Elaine, $20 \mathrm{~A}$ )

- curso foi ótimo, aprendemos muito sobre os conhecimentos em Geografia, além do Silas ser super bacana, 
- Achei a metodologia desse ano diversificada, fazendo com que nos interessássemos pelos assuntos do cotidiano. (Manuela e Maria de Fátima, $2^{\circ}$ B)

- Foi legal, bem aproveitado. Nunca tínhamos aprendido dessa forma. (Marcelo e Karin, 21/11/97, 20 B)

- O ensino deste ano foi bom, por termos saído da rotina de uma aula, discutimos assuntos atuais que estão presentes. Esse ano foi diferente do que nós estudamos, pois nos anos passados era à base de livros, que devíamos decorar e não entendiamos quase nada. (Liliane e Fernanda, $2^{\circ} \mathrm{B}$.

- A matéria foi muito diferente, porque falamos de coisas muito importantes e aprendemos muito e ficamos atualizados. (Ana Karina e Marlene, 20 B)

- O seu modo de dar aula deixa os alunos um pouco mais livres para questionarmos... é uma maneira diferente... seu jeito de dar aula, dando atenção a todos os alunos, e se preocupando com todos nós. Fazendo de uma aula de Geografia (alguma coisa) descontraída e interessante. (Célia e Adriana, $2^{\circ}$ B)

- O curso, este ano para mim, foi um dos melhores, porque o professor contribuiu com as suas maneiras de dar aula e com seu comportamento enérgico, mas também descontraido. Obrigado, professor. Parabéns!! (Raimundo e Marcelo, $2^{\circ} \mathrm{B}$ )

- Os debates, que revelam as diversas opiniões, são importantes para o esclarecimento e ajudam a abrir as mentes do pessoal. Os trabalhos e exposições desenvolvem a capacidade de pesquisar e interesse pelo assunto, proporcionando um maior desempenho por parte dos alunos. (Maurício e Daniel, $2^{\circ} \mathrm{C}$ )

- Gostamos e aprovamos, porque nós participamos mais, discutimos vários aspectos, várias idéias, e é muito importante para uma melhor compreensão da realidade. (Genésio e Maxwell, $2^{\circ} \mathrm{C}$ )

- A metodologia de ensino foi bastante boa. Os debates, as expressões de opiniões fazem-nos abrir uma visão "crítica" do mundo, além de nos proporcionar conhecimentos.. (Carlos, $2^{\circ} \mathrm{C}$ )

- O curso desse ano foi bom porque com as apresentações de seminários, nós tivemos uma melhor maneira de se expressar e de entender a matéria. (Robson e Fabiano, $2^{\circ}$ D)

- O curso de Geografia efetuado este ano foi muito estimulante. Através de debates, conseguimos absorver muito mais conteúdo do que em simples aulas teóricas. O curso foi ótimo!!! (Juliana e Daniela, $2^{\circ}$ D)

- O curso foi muito criativo. Professor, continue dando suas aulas dessa forma alegre e brincalhona. Gostamos muito de você... (Juliana e Dalvina, $2^{\circ} \mathrm{D}$ )

- Nós achamos que o professor se interessou em explicar para que todos aprendessem, não para que todos decorassem. (Flávia e Érika, $2^{\circ}$ D)

- O curso, em geral, foi muito bom, pois discutimos temas polêmicos e que nos incentivou a expor nossas idéias e o nosso ponto de vista. As aulas dinâmicas incentivaram os alunos a terem uma certa amizade com o professor, e isso não é muito comum, mas gostamos da experiência. (Rogério e Eduardo, $2^{\circ} \mathrm{D}$ )

- A matéria não foi fácil, mas o professor nos ajudou a entender um pouco (Alessandra). A matéria acabou sendo menos difícil com a forma de explicar... (Marília, $2^{\circ} \mathrm{D}$ )

- O curso foi diferente dos anos anteriores, pois foram valorizados os trabalhos, seminários, participação e não só as provas, tornando este ano muito interessante. (Clayton e Fernando, 20 D)

- Achamos o curso super interessante, o método de ensino foi muito bom, pois nossas aulas foram mais práticas do que teóricas, nos ajudando assim a ter um melhor desempenho. Queremos o professor no $3^{\circ}$ ano que vem! (Renata e Sandra, $20 \mathrm{E}$ )

- Foi muito interessante, porque tratamos muito mais de problemas atuais(bem terra), do que a Geografia antiga. Isso nos leva a nos informarmos sobre as condições atuais e futuras. (Morgana e Juliana, $\left.2^{\circ} \mathrm{E}\right)$

- Foi um bom curso, com muita discussão e debate, isso é muito importante. A classe assimilou bem os ensinamentos do professor Silas, participando das aulas e mantendo uma certa regularidade. Achamos que todas as aulas deveriam ser assim: professor e aluno discutindo sobre a matéria, não ficar cobrando e respondendo questionário. Foi um ano muito bom. (João Luiz e Thiago, $2^{\circ} \mathrm{E}$ )

- Gostei (do tema): Imigrantes e Migrantes, talvez por mexer com nossos antepassados e descobrir coisas legais. E dos trabalhos sobre Prevenção e Anticoncepcionais. Não gostei: não tem uma coisa que não tenha gostado, apenas teve coisas que gostei mais. (Sabrina, $30 \mathrm{~A}$ )

- Esta metodologia de avaliar os alunos ... no fim do ano me agradou muito particularmente. Suas aulas são dinâmicas e sua direção é muito boa. Gostei das matérias que tratavam das imigrações e migrações. Não tem nenhuma matéria que eu não tenha gostado. (Ana Carolina, $3^{\circ} \mathrm{A}$ )

- A metodologia é diferente, mas bem produtiva, não fica monótono e cansativo. Os assuntos foram interessantes 


\section{Quadro 3 (continuação)}

e bem proveitosos. Todas as atividades foram boas. (Priscila, $30 \mathrm{~A}$ )

Eu gostei muito do trabalho em conjunto, pois nos possibilitou uma integração mais prazerosa, onde pudemos trocar os conhecimentos. O trabalho, em coletividade, deixa o conteúdo da matéria mais fixado em nossas mentes e em nossas vidas também. Valeu! Geografia do $3^{\circ}$ ano, vou guardar com muito carinho esse assunto. (Sílvia, $30 \mathrm{~A}$ )

- Na minha opinião, Geografia foi a matéria que mais aprendi este ano. O conteúdo da matéria foi bom. Todas as perguntas que caíram no vestibular deste ano, eu lembrava que o assunto tinha sido comentado na sala de aula. (Bianca, $3^{\circ} \mathrm{A}$ )

- As atividades em grupo foram muito legais, pois começamos a ver outras visões além da nossa. E os debates foram ótimos. E não gostei dos trabalhos para casa, pois trabalho e no fim de semana não sobra tempo para poder elaborar um bom trabalho. (Gledson, $30 \mathrm{~B}$ )

- Bem, professor, uma atividade que gostei e achei importante foi aquela sobre métodos anticoncepcionais, porque muitas amigas que tenho já engravidaram e se arrependeram até hoje! (Cláudia R., 30 B)

- Uma atividade que eu gostei muito foi aquela em que nós, os alunos, tivemos que tirar fotos sobre diversos temas e que depois nos renderam reconhecimentos de professores e de outras pessoas... (Cláudia N., $3^{\circ} \mathrm{B}$ )

- Gostei dos debates sobre o sexualismo, da matéria de industrialização... (Fabiana, $3^{\circ} \mathrm{B}$ )

- A que eu mais gostei foi essa que acabei de fazer. Os professores só dão provas valendo notas sérias, e temos que decorar diversas coisas. Mas esta é a primeira que faço para avaliar-me de verdade. A atividade que menos gostei foi a do mapa (de fazer o caminho de onde alguém da minha família veio). (Débora, 30 B)

- Gostei do trabalho que foi feito para a Semana Cultural que incentivou e estimulou os alunos a descobrirem um novo lado de si: o lado "artístico". Não tenho o que reclamar, só de mim, pois não gostei do meu desempenho; sei que sou capaz de desempenhar-me mais, apesar das dificuldades. (Viviane, $3^{\circ} \mathrm{B}$ )

- Eu achei muito bom, foi bem diferente, tendo bastante coisas em grupo, a aula fica mais divertida. Gostei de tudo, principalmente, do estudo sobre os métodos contraconceptivos e daquele outro trabalho sobre imigração européia e sobre a migração que nós tivemos que desenhar. Gostei também porque nós pudemos mostrar tudo isso na Semana Cultural. Valeu! (Juliana, $3^{\circ} \mathrm{B}$ )

Adorei ter feito o trabalho sobre poluição (fotos, cartazes) e não gostei muito da aula para fazer os mapas de migração (principalmente o que falava de migração da minha família). (Roberta, $3^{\circ} \mathrm{B}$ )

Eu achei muito interessante e proveitoso o trabalho que fizemos nas fotos sobre poluição e outros temas. Eu, particularmente, aprendi muito com este trabalho. Achei interessante também a abordagem do assunto sobre métodos anticoncepcionais, pois eu acho que para nós, jovens, tudo é muito importante, principalmente, saber sobre uma coisa que acontece com todos no sexo, aprendendo como colocar corretamente a camisinha, saber os melhores métodos de prevenção. Não só para ter cuidado com a AIDS, mas também (para evitar) uma gravidez não planejada. (Fernanda, $3^{\circ} \mathrm{B}$ )

- Gostei de todas as atividades, principalmente, da Semana Cultural. Aprendi muito. A sessão de fotos estava simplesmente maravilhosa. Obrigada e parabéns pelo ensino. (Cida, $3^{\circ} \mathrm{B}$ )

- Realmente, a metodologia me proporcionou aprender um pouco da Geografia, de forma diferente e agradável. Gostei de estudar Geografia, pela primeira vez, com responsabilidade. A atividade da Semana Cultural foi a que eu mais gostei, e não gostei desta prova. (Carlos, $30 \mathrm{C}$ )

- O trabalho das fotos foi super diferente. Tenho certeza de que todo mundo adorou muito fazer. Fora os convites que tivemos depois para ir apresentá-lo na USP e no interior. (Renata, $30 \mathrm{C}$ )

\section{REFERÊNCIAS BIBLIOGRÁFICAS}

ABDALLA, Maria de Fátima B. Relatório de pesquisa "A didática na licenciatura - um estudo dos efeitos e um programa de curso na atividade docente de alunos egressos da licenciatura” (coordenação Pimenta, Selma G.). FE-USP, 1997.

Formação e desenvolvimento profissional do professor: o aprender da profissão (um estudo em escola pública). 2000. Tese (Doutorado) - Faculdade de Educação da Universidade de São Paulo.

BAKHTIN, Mikhail. Questões de literatura e estética (A teoria do romance). São Paulo: UNESP/HUCITEC, 1988. Marxismo e filosofia da linguagem. 7. ed. Trad. Michel Lahud \& Yara F. Vieira. São Paulo: Hucitec, 1995.

BOURDIEU, Pierre. Algumas propriedades dos campos. In: BORDIEU, P. Questões de Sociologia. Rio de Janeiro: Marco Zero, 1983. . A economia das trocas simbólicas. 2. ed. São Paulo: Perspectiva, 1987.

O poder simbólico. Rio de Janeiro: Bertrand Brasil, 1989.

. Coisas ditas. São Paulo: Brasiliense, 1990. 
. As regras da arte. Trad. Maria Lúcia Machado. São Paulo: Companhia das Letras, 1996.

. Razões práticas: sobre a teoria da ação. Campinas: Papirus, 1997.

CANÁRIO, Rui. A escola: o lugar onde os professores aprendem. Universidade de Aveiro. I Congresso Nacional de Supervisão na Formação, 18-20 de dezembro de 1997 (mimeo).

CORTELLA, Mário Sergio. A Escola e o conhecimento: fundamentos epistemológicos e políticos. São Paulo, Cortez, 1998.

CUNHA, Maria Isabel da. O bom professor e sua prática. 5. ed. Campinas: Papirus, 1995.

. Conta-me agora! As narrativas como alternativas pedagógicas na pesquisa e no ensino. Revista da Faculdade de Educação.

São Paulo, v. 23, n.1/2, p. 185-195, jan/dez. 1997.

DEMO, Pedro. Desafios modernos da educação. 6. ed. Petrópolis: Vozes, 1997.

ENGUITA, Mariano. O Magistério numa Sociedade em Mudança. In: VEIGA, I.P.A. (org.). Caminhos da profissionalização do Magistério. Campinas: Papirus, 1998.

FREIRE, Paulo. Pedagogia da autonomia: saberes necessários à prática educativa. 2. ed. São Paulo: Paz e Terra, 1997.

HELLER, Agnes. Sociología de la vida cotidiana. 3. ed. Barcelona: Ediciones Península, 1977.

. Cotidiano e a História. 4. ed. Rio de Janeiro: Paz e Terra, 1992.

KINCHELOE, Joe L. A formação do professor como compromisso político: mapeando o pós-moderno. Trad. Nize M.C. Pellanda. Porto Alegre: Artes Médicas, 1997.

LEFEBVRE, Henri. Critique de la vie quotidienne I - Introduction. Paris: L'arche Éditeur, 1958. . A vida cotidiana no mundo moderno. São Paulo: Ática, 1991.

. Lógica formal/Lógica Dialética. 6. ed. Trad. Carlos Nelson Coutinho. Rio de Janeiro: Civilização Brasileira, 1995.

LIBÂNEO, José Carlos. Adeus professor, adeus professora? Novas exigências educacionais e profissão docente. São Paulo: Cortez Editora, 1998. (Coleção Questões da Nossa Época; v. 67).

LINHARES, Célia Frazão Soares. A Escola e seus profissionais. 2. ed. Rio de Janeiro, Agir, 1988.

MARCELO GARCÍA, Carlos. Formación del professorado para el cambio educativo. Barcelona: Promociones y Publicaciones Universitarias/PPU, 1994.

MARIN, Alda Junqueira. Desenvolvimento profissional docente: início de um processo centrado na escola. In: VEIGA, I.P.A. (org.). Caminhos da profissionalização do Magistério. Campinas: Papirus, 1998, p. 137-152.

MORAIS, Regis de (org.). Sala de aula: que espaço é esse? 10. ed. Campinas: Papirus, 1997.

NÓVOA, António (coord). Os professores e a sua formação. Lisboa: Publicações Dom Quixote, 1992 a. . Vidas de professores. Porto: Porto, $1992 \mathrm{~b}$.

PENIN, Sonia Teresinha de Sousa. Cotidiano e escola: a obra em construção (o poder das práticas cotidianas na transformação da escola). São Paulo: Cortez, 1989.

. A aula: espaço de conhecimento, lugar de cultura. Campinas: Papirus, 1997.

PERRENOUD, Philippe. Práticas pedagógicas, profissão docente e formação: perspectivas sociológicas. Lisboa: Publicações Dom Quixote, Instituto de Inovação Educacional, 1993.

. Oficio de aluno e sentido do trabalho escolar. Trad. Júlia Ferreira. Porto: Porto Editora Ltda., 1995.

PIMENTA, Selma Garrido. A Didática como mediação na construção da identidade do professor: uma experiência de ensino e pesquisa na licenciatura. In: ANDRÉ, M.E.D.A. \& OLIVEIRA, M.R.N.S. (orgs). Alternativas do ensino de Didática. Campinas: Papirus, 1997, p.37-69.

. A prática (e a teoria) docente ressignificando a Didática. In: OLIVEIRA, M.R.N.S. (org.). Confluências e divergências entre Didática e Cuxrículo. Campinas: Papirus, 1998, p. 153-176.

RODRIGUES, Ângela; ESTEVES, Manuela. A análise de necessidades na formação de professores. Porto: Porto, 1993.

SANMAMED, Mercedes González. Formación Docente: perspectivas desde el desarrollo del conocimiento y la socialización profesional. Barcelona: Promociones y Publicaciones Universitarias/PPU, 1995.

SCHÖN, Donald. Educating the reflective practitioner. Toward a new desing for teaching and learning in the professions. San Francisco: Jossey Bass, 1987.

SILVA JR, Celestino A. Escola pública como local de trabalho. São Paulo: Cortez, 1991.

ZEICHNER, Ken. Novos caminhos para o practicum: uma perspectiva para os anos 90. In NÓVOA, A. (org.). Os professores e a sua formação. Lisboa: Publicações Dom Quixote, 1992. 